\title{
The First Noonan Syndrome Gene: PTPN11, Which Encodes the Protein Tyrosine Phosphatase SHP-2
}

\author{
A review of: Tartaglia M, Mehler EL, Goldberg R et al. 2001 Mutations in PTPN11, encoding the protein tyrosine \\ phosphatase SHP-2, cause Noonan syndrome. Nat Genet 29:465-468; and Tartaglia M, Kalidas K, Shaw A et al. 2002 \\ PTPN11 mutations in Noonan syndrome: molecular spectrum, genotype-phenotype correlation, and phenotypic \\ heterogeneity. Am J Hum Genet 70:1555-1563
}

$\mathrm{N}$ OONAN SYNDROME IS a common autosomal dominant disorder characterized by unusual facial features, short stature, skeletal anomalies, and defects of the heart, the most common of which are pulmonary valve dysplasia and hypertrophic cardiomyopathy $(1,2)$. Intellectual handicap, usually mild, and bleeding diatheses, are also found. Incidence is said to be 1 in 1000-2500 births. In 1994, Noonan syndrome was mapped to $12 \mathrm{q} 24.1$ and genetic heterogeneity was documented (3). The search for a causative gene has recently borne fruit.

In 2001, Tartaglia and colleagues, representing a multicenter consortium, used a positional candidacy approach to demonstrate mutations in PTPN11 in two moderate sized families and 11 unrelated individuals, $50 \%$ of those tested (4). PTPN11 was considered a candidate gene for Noonan syndrome because of its location, and because it's protein product, SHP-2, is a key component of several signal transduction pathways that control protean developmental processes, particularly cardiac semilunar valvulogenesis.

PTPN11 is composed of two tandemly arranged amino-terminal src-homology 2 (SH-2) domains (N-SH2 and C-SH2), a phosphotyrosine phosphatase (PTP) domain and a carboxy-terminal tail (5). The missense mutations cluster in interacting portions of the amino N-SH2 domain and the PTP domains, which are involved in switching the protein between its inactive and active conformations. These amino acid substitutions are found in exons 3 and 8 , they have not been found in more than 200 controls, and they affect highly conserved regions. An energetics-based structural analysis of two N-SH2 mutants indi-

\section{Judith Allanson}

cates there may be a significant shift of the equilibrium favoring the active conformation, implying a gain of function change. Functional data support the conclusions of these energetic-based structural analyses. It seems likely that Noonan syndrome occurs due to excessive SHP-2 activity, which may result in increased or decreased signaling through specific pathways.

Tartaglia and colleagues have gone on to evaluate the PTPN11 gene in 119 unrelated individuals with Noonan syndrome, 49 from small families and 70 sporadic cases. Mutations have been found in $45 \%$ of this cohort. There is a significantly higher prevalence of mutations in familial cases. The mutations are missense exonic changes, several of them recurrent. The vast majority continue to be located in or around the interacting surfaces of the $\mathrm{N}$ $\mathrm{SH} 2$ and PTP functional domains, but mutations in the $\mathrm{C}-\mathrm{SH} 2$ domain and in the peptide linking the N-SH2 and C-SH2 domains are now also described. No attempt has yet been made to look for large intragenic deletions or duplications, changes in the 3ÚTR, or promotor/enhancer regions.

That PTPN11 mutations should cause varied congenital anomalies, such as those observed in Noonan syndrome, is consistent with the well established role of this protein in development - including mesodermal patterning, limb development, hemopoietic cell differentiation, and signaling mediated by epidermal growth factor receptor during semilunar valvulogenesis. As might be expected, pulmonic stenosis is more prevalent among the subjects with mutations than in the group without mutations. The opposite is true for individuals with hypertrophic cardiomyopathy. The prevalence of other heart defects, short stature, skeletal anomalies, cryptorchidism, and developmental delay does not differ between the two groups. An understanding of the increased prevalence of hypertrophic cardiomyopathy in other genetic forms of Noonan syndrome awaits elucidation of those disease genes.

The next step will be to evaluate syndromes with features that overlap with those of Noonan syndrome, such as cardio-facio-cutaneous syndrome and LEOPARD syndrome, to define whether these conditions are distinct, allelic, or extreme phenotypes of this highly variable disorder.

1. Allanson JE 1987 Noonan syndrome. J Med Genet 24:9-13

2. Allanson JE 2001 Noonan syndrome. In: Cassidy SB, Allanson JE (eds) Management of Genetic Syndromes. Wiley, New York, pp 253-268

3. Jamieson CR, van der Burgt I, Brady AF, van Reen M, Elsawi MM, Hol F, Jeffery S, Patton MA, Mariman E 1994 Mapping a gene for Noonan syndrome to the long arm of chromosome 12 . Nat Genet 8: 357-360

4. Tartaglia M, Mehler EL, Goldberg R, Zampino G, Brunner HG, Kremer H, van der Burgt I, Crosby AH, Ion A, Jeffery S, Kalidas K, Patton MA, Kucherlapati RS, Gelb BD 2001 Mutations in PTPN11, encoding the protein tyrosine phosphatase SHP-2, cause Noonan syndrome. Nat Genet 29:465-468

5. Tartaglia M, Kalidas K, Shaw A, Song X, Musat DL, van der Burgt I, Brunner HG, Bertola DR, Crosby A, Ion A, Kucherlapati RS, Jeffery S, Patton MA, Gelb BD 2002 PTPN11 mutations in Noonan syndrome: molecular spectrum, genotype-phenotype correlation, and phenotypic heterogeneity. Am J Hum Genet 70:1555-1563

Department of Genetics

Children's Hospital of Eastern Ontario

401 Smyth Road

Ottawa, Ontario

K1H 8 L1

Canada

DOI: 10.1203/01.PDR.0000035197.12622.58 